\title{
Association between self-rated oral appearance and the need for dental prostheses among elderly Brazilians
}

\section{Emília Araújo Vilela (a) \\ Andréa Maria Eleutério de Barros Lima Martins ${ }^{(\mathbf{b})}$ \\ Sandhi Maria Barreto(c) \\ Andréa Maria Duarte Vargas ${ }^{(d)}$ \\ Raquel Conceição Ferreira ${ }^{(\mathrm{d})}$}

\footnotetext{
(a) Programa de Pós-graduação em Ciências da Saúde, Univ Estadual de Montes Claros Unimontes, Montes Claros, MG, Brasil.

(b) Centro de Ciências Biológicas e da Saúde, Departamento de Odontologia, Univ Estadual de Montes Claros - Unimontes, Montes Claros, MG, Brasil.

(c) Departamento de Medicina Preventiva e Social, Faculdade de Medicina, Universidade Federal de Minas Gerais UFMG, Belo Horizonte, MG, Brasil.

(d) Departamento de Odontologia Social e Preventiva, Faculdade de Odontologia, Univ Federal de Minas Gerais - UFMG, Belo Horizonte, MG, Brasil.
}

Declaration of Interests: The authors certify that they have no commercial or associative interest that represents a conflict of interest in connection with the manuscript.

Corresponding Author: Raquel Conceição Ferreira E-mail: ferreira_rc@hotmail.com

Submitted: Oct 29, 2012

Accepted for publication: Feb 08, 2013

Last revision: Feb 16, 2013

\begin{abstract}
We investigated the association between poor self-rated oral appearance and the need for dental prostheses among elderly Brazilians. National data from an epidemiological survey on oral health in Brazil conducted from 2002 to 2003 by the Ministry of Health (SB, Brazil) with a multistage random sample of 4,839 individuals aged 65-74 years in 250 towns were analyzed. The dependent variable was self-rated oral appearance, dichotomized into "poor" (poor/very poor) and "good" (fair/good/very good). The main independent variable was the need for an upper or lower dental prosthesis. Other variables included sociodemographic characteristics, approach to dental care, oral health conditions, and self-reported oral disadvantage. Data were analyzed using the chi-square test and Poisson regression models at a 95\% significance level. The prevalence of poor self-rated oral appearance was $20.6 \%$ and was higher in the elderly who needed a partial or complete upper or lower prosthesis, independent of other variables. This prevalence was associated with age, the use of dental services, access to information about oral disease prevention, number of decayed teeth, self-perception of the need for treatment, dental pain, chewing ability, and the perception that oral health affects relationships with other people. The elderly who needed dental prostheses had a higher prevalence of poor self-rated oral appearance than those who did not need any.
\end{abstract}

Descriptors: Oral Health; Dental Prosthesis; Esthetics; Dental Care for Aged.

\section{Introduction}

Self-rated health corresponds to one's perception of personal health status in the social, cultural, and historical context. ${ }^{1}$ It is a valid, reliable, and cost-effective indicator of perceptions of general and oral health. ${ }^{2}$ Several studies have identified factors associated with self-rated oral health in the elderly, including self-esteem, life satisfaction, income, dental attendance, sex, perception of treatment need, dental pain, untreated caries, and prosthetic status and need..$^{3-6}$

In 2003, a pioneering study in Brazil used self-rated questions to evaluate subjects' perceptions of oral health, chewing, speech, social networking, and appearance. ${ }^{7}$ Using data from this survey, 3 studies investigated the factors associated with self-rated oral health in the elderly population and found that self-rated oral appearance was the variable most 
strongly associated with self-rated oral health. ${ }^{3-5}$ Another study evaluated the factors associated with poor self-perception of mastication. ${ }^{8}$

Elderly Brazilians were reported to have poor oral health, with a high prevalence of edentulism and need for dental prosthetics. ${ }^{7}$ In 2003, approximately $50 \%$ of the elderly population required 1 or 2 complete prostheses. Tooth loss and the need for prostheses were associated with poor self-rated oral health and mastication. ${ }^{3-5,8}$ However, to our knowledge, no studies have evaluated factors associated with self-rated oral appearance among the elderly.

Meng et al. ${ }^{9}$ assessed the satisfaction with dental appearance in adults, adopting a multidimensional conceptual model of oral health. Their results demonstrated that satisfaction with appearance was associated with sociodemographic characteristics, approach to dental care, oral disease, and oral disadvantage.

Among the elderly, aesthetic rather than functional factors dictate a patient's subjective need to replace missing teeth. ${ }^{10}$ Self-rated oral appearance has also gained increasing interest among researchers and dental clinicians because patients and dentists often evaluate dental aesthetics differently. ${ }^{11}$ Considering the large numbers of teeth lost among Brazilian elderly ${ }^{7}$ and the possibility of rehabilitation with a dental prosthesis, we investigated the association between poor self-rated oral appearance and the need for a dental prosthesis in the elderly Brazilian population.

\section{Methodology}

This cross-sectional study used the database of the epidemiological survey on oral health in Brazil conducted from 2002 to 2003 by the Ministry of Health. In total, 108,921 individuals participated in the survey. A multistage cluster sampling design consisted of a random selection of 250 towns from all the Brazilian states, stratified by Brazilian macroregions (North, Northeast, Midwest, Southeast, and South) and population size $(<5000$ inhabitants, 5001-10,000, 10,001-50,000, 50,001-100,000, and $>100,001)$. The sampling was designed to obtain a representative sample of the Brazilian regions, towns, and age groups. A probabilistic sample selection method was adopted. We selectively analyzed the data of individuals aged 65 to 74 years, the age range recommended by the World Health Organization for assessing the oral health status of the elderly. ${ }^{12}$ The data were collected by oral examinations and structured interviews conducted in-home by trained dental surgeons. The oral examinations were performed under natural illumination using flat mirrors, periodontal probes, and wooden spatulas.

The dependent variable was self-rated oral appearance (SROA), assessed by the question, "How would you classify the appearance of your teeth and gums?" The response options were "good" (fair/ good/very good) or "poor" (very poor/poor). The main independent variable was the need for an upper and/or lower prosthesis; this variable was categorized on the basis of the results of oral examinations as follows:

- 0 , does not need a dental prosthesis;

- 1 , needs a fixed or removable prosthesis to replace 1 element;

- 2 , needs a fixed or removable prosthesis to replace more than 1 element;

- 3 , needs a combination of fixed and/or removable prosthesis to replace 1 or more elements; and

- 4 , needs a complete prosthesis.

The other independent variables were combined into 4 subgroups according to the theoretical model proposed by Meng et al. ${ }^{9}$ (Figure 1).

Sociodemographic characteristics:

- information on Brazilian macroregion,

- place of residence,

- age,

- sex,

- self-declared skin color,

- years of education, and

- per capita income in reals (US\$1.0 = R \$3.20).

Approach to dental care:

- type of dental service used,

- access to information about oral disease prevention, and

- time since the last dental visit. 
Figure 1 - Conceptual theoretical model of Meng et al. ${ }^{9}$.

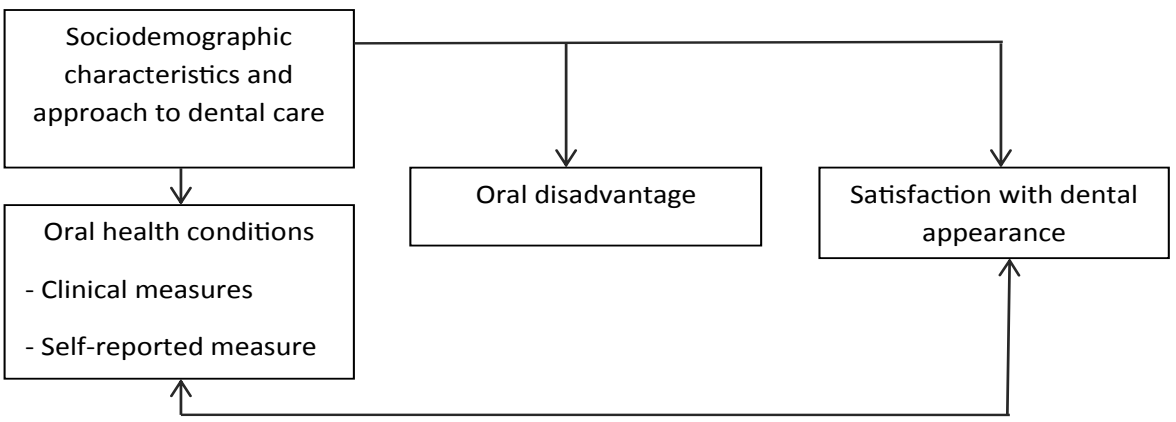

Oral conditions:

- numbers of present and decayed teeth and

- perceived and actual needs for dental treatment. The need for dental treatment was evaluated according to the following criteria: ${ }^{12}$

- 0, no need;

- 1 , restoration of 1 ,

- 2, or more surfaces;

- 3, crown placement for any reason;

- 4, veneer placement;

- 5, pulp treatment and restoration;

- 6, extraction;

- 7, remineralization of white spot; and

- 8, sealant treatment.

The subjects with codes 1 to 8 were categorized as requiring dental treatment.

Self-reported oral disadvantages:

- Dental and gingival pain within the last 6 months was categorized as

- absent (no pain) or

- present (slight, moderate, or substantial pain).

- Chewing ability (good or poor) and damage to relationships with other people because of tooth or gum conditions were also considered.

The survey was approved by CONEP (Process no. 581/2000). Bivariate and multivariate analyses were conducted using a Poisson regression model to produce direct estimates of all prevalence ratios (PR; 95\% CI) and the chi-square test for statistical significance. Variables with $p<0.25$ in the bivariate analysis were included in the multivariate analysis in decreasing order of significance. In the final
Table 1 - Distribution of the elderly population in Brazil in 2003 according to the need for a dental prosthesis.

\begin{tabular}{l|c|c}
\hline \multicolumn{1}{c|}{ Need for a dental prosthesis } & $\begin{array}{c}\text { Upper (\%) } \\
(\mathrm{n}=4830)\end{array}$ & $\begin{array}{c}\text { Lower (\%) } \\
(\mathrm{n}=4826)\end{array}$ \\
\hline Does not need & 68.7 & 44.3 \\
\hline $\begin{array}{l}\text { Fixed or removable partial prosthesis } \\
\text { (RPP) to replace 1 element }\end{array}$ & 1.3 & 1.6 \\
\hline $\begin{array}{l}\text { Fixed or RPP to replace more than 1 } \\
\text { element }\end{array}$ & 6.3 & 13.6 \\
\hline $\begin{array}{l}\text { Combination of fixed and/or RPP to } \\
\text { replace 1 or more elements }\end{array}$ & 9.2 & 18.3 \\
\hline \begin{tabular}{l} 
Complete prosthesis \\
\hline
\end{tabular}
\end{tabular}

adjusted model, only the variables significantly associated with SROA with $p<0.05$, were used. All of the analyses were performed using the Predictive Analytics Software version 18.0 for Windows (IBM Corporation, Armonk, USA).

\section{Results}

A total of 5,349 people were interviewed and examined; of these subjects, 510 individuals did not report their SROA and were thus excluded from the analysis. The prevalence rates of poor and good SROA were $20.6 \%$ and $89.4 \%$, respectively. Upper and lower prostheses were required in $31.3 \%$ and $55.7 \%$ of the patients, respectively (Table 1 ).

In the bivariate analysis, all independent variables were associated with poor SROA at $p<0.25$ with the exception of the residence location (Table 2).

In the final model, the prevalence of poor SROA, independent of other variables, was higher among those who needed a partial or complete upper or 
Table 2 - Prevalence of poor self-rated oral appearance among elderly Brazilians and the results of the bivariate analysis. (continued on next page)

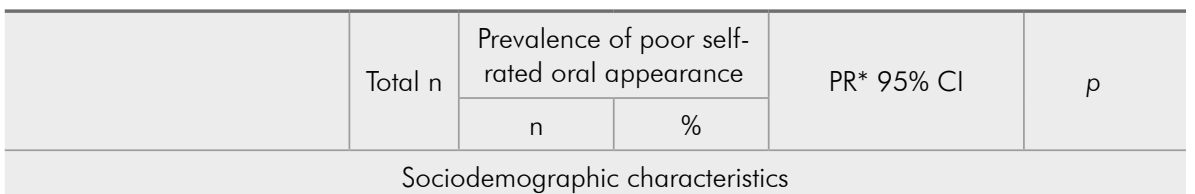

Brazilian macroregion

\begin{tabular}{l|c|c|c|c|c}
\hline$\cdot$ Southeast & 958 & 144 & 15.0 & 1 & \\
\hline$\cdot$ South & 1307 & 183 & 14.0 & $0.93(0.76-1.14)$ & 0.491 \\
\hline$\cdot$ Midwest & 648 & 133 & 20.5 & $1.37(1.10-1.69)$ & 0.004 \\
\hline - Northeast & 1256 & 345 & 27.5 & $1.83(1.53-2.18)$ & 0.000 \\
\hline - North & 670 & 193 & 28.8 & $1.92(1.58-2.32)$ & 0.000 \\
\hline
\end{tabular}

Residence location

\begin{tabular}{l|c|c|c|c|c}
\hline - Urban area & 4222 & 873 & 20.7 & 1 & \\
\hline - Rural area & 615 & 123 & 20.0 & $0.97(0.82-1.15)$ & 0.699 \\
\hline
\end{tabular}

Age range, years

\begin{tabular}{c|c|c|c|c|c}
$\cdot 65-69$ & 2929 & 644 & 22.0 & 1 & \\
\hline$\cdot 70-74$ & 1910 & 354 & 18.5 & $0.84(0.75-0.95)$ & 0.004 \\
\hline
\end{tabular}

Sex

\begin{tabular}{l|c|c|c|c|c}
\hline- Female & 2945 & 565 & 19.2 & 1 & \\
\hline- Male & 1894 & 433 & 22.9 & $1.19(1.07-1.33)$ & 0.002 \\
\hline
\end{tabular}

Self-declared skin color

\begin{tabular}{l|c|c|c|c|c}
\hline$\cdot$ White & 2366 & 380 & 16.1 & 1 & \\
\hline$\cdot$ Nonwhite & 2457 & 616 & 25.1 & $1.56(1.39-1.75)$ & $<0.001$ \\
\hline Years of education & 968 & 163 & 16.8 & 1 & \\
\hline-25 & 2203 & 434 & 19.7 & $1.17(0.99-1.38)$ & 0.060 \\
\hline$-1-4$ & 1668 & 401 & 24.0 & $1.43(1.21-1.68)$ & $<0.001$ \\
\hline-0 &
\end{tabular}

Per capita income in reais

\begin{tabular}{l|c|c|c|c|c}
\hline$\geq 201.00$ & 1441 & 211 & 14.6 & 1 & \\
\hline$\cdot 100.00$ to 200.00 & 1906 & 370 & 19.4 & $1.33(1.14-1.55)$ & $<0.001$ \\
\hline$\cdot 0$ to 99.00 & 1461 & 409 & 28.0 & $1.91(1.65-2.22)$ & $<0.001$ \\
\hline \multicolumn{5}{c}{ Approach to dental care }
\end{tabular}

Type of dental service used

- Private

\begin{tabular}{|c|c|c|c|c|}
\hline 2414 & 368 & 15.2 & 1 & \\
\hline 2026 & 474 & 23.4 & $1.54(1.36-1.74)$ & $<0.001$ \\
\hline 188 & 90 & 47.9 & $3.14(2.63-3.75)$ & $<0.001$ \\
\hline
\end{tabular}

- Public

- Never used

Access to information about oral disease prevention

\begin{tabular}{l|l|l|l|c|c}
\hline$\cdot$ Yes & 1983 & 323 & 16.3 & 1 & \\
\hline$\cdot$ No & 2853 & 675 & 23.7 & $1.45(1.29-1.64)$ & $<0.001$ \\
\hline
\end{tabular}

Time since the last dental visit

\begin{tabular}{l|c|c|c|c|c}
\hline$-\leq 2$ years & 1442 & 257 & 17.8 & 1 & \\
\hline$-\geq 3$ years & 3195 & 647 & 20.3 & $1.14(0.99-1.30)$ & 0.055 \\
\hline- Never & 188 & 90 & 47.4 & $2.69(2.23-3.24)$ & $<0.001$ \\
\hline
\end{tabular}


Table 2 - (continued)

\begin{tabular}{|c|c|c|c|c|c|}
\hline & \multirow[t]{2}{*}{ Total $n$} & \multicolumn{2}{|c|}{$\begin{array}{l}\text { Prevalence of poor self- } \\
\text { rated oral appearance }\end{array}$} & \multirow[t]{2}{*}{$\mathrm{PR}^{*} 95 \% \mathrm{Cl}$} & \multirow[t]{2}{*}{$p$} \\
\hline & & $\mathrm{n}$ & $\%$ & & \\
\hline \multicolumn{6}{|c|}{ Oral health conditions } \\
\hline \multicolumn{4}{|c|}{ - Number of permanent teeth present** } & $1.02(1.01-1.02)$ & $<0.001$ \\
\hline \multicolumn{4}{|c|}{ - Number of decayed permanent teeth** } & $1.09(1.08-1.10)$ & $<0.001$ \\
\hline \multicolumn{6}{|l|}{ Need for dental treatment } \\
\hline - No & 3286 & 485 & 14.8 & 1 & \\
\hline - Yes & 1553 & 513 & 33.0 & $2.24(2.01-2.49)$ & $<0.001$ \\
\hline \multicolumn{6}{|c|}{ Need for an upper prosthesis } \\
\hline - Does not need & 3320 & 449 & 13.6 & 1 & \\
\hline - Needs a fixed or RPP & 809 & 285 & 35.2 & $2.61(2.29-2.96)$ & $<0.001$ \\
\hline $\begin{array}{l}\text { Needs a complete } \\
\text { prosthesis }\end{array}$ & 701 & 261 & 37.2 & $2.75(2.42-3.13)$ & $<0.001$ \\
\hline \multicolumn{6}{|l|}{ Need for a lower prosthesis } \\
\hline - Does not need & 2137 & 237 & 11.1 & 1 & \\
\hline - Needs a fixed or RPP & 1615 & 461 & 28.5 & $2.56(2.32-2.97)$ & $<0.001$ \\
\hline $\begin{array}{l}\text { - Needs a complete } \\
\text { prosthesis }\end{array}$ & 1074 & 295 & 27.5 & $2.48(2.12-2.89)$ & $<0.001$ \\
\hline
\end{tabular}

Self-perception of the need for dental treatment

\begin{tabular}{c|c|c|c|c|c}
\hline- No & 2161 & 210 & 9.7 & 1 & \\
\hline- Yes & 2669 & 788 & 29.5 & $3.04(2.64-3.50)$ & $<0.001$ \\
\hline \multicolumn{6}{c}{ Self-reported oral disadvantage } \\
\hline
\end{tabular}

Dental and gingival pain within the last 6 months

\begin{tabular}{l|c|c|c|c|c}
\hline$\cdot$ Absent & 3700 & 619 & 16.7 & 1 & \\
\hline $\begin{array}{l}\text { - Present } \\
\text { Chewing ability }\end{array}$ & 1138 & 378 & 33.2 & $1.99(1.78-2.22)$ & $<0.001$ \\
\hline $\begin{array}{l}\text { - Good } \\
\text { - Poor }\end{array}$ & 3643 & 350 & 9.6 & 1 & \\
\hline
\end{tabular}

Oral health affects relationships with other people

\begin{tabular}{l|l|c|c|c|c}
\hline- No & 3163 & 401 & 12.7 & 1 & \\
\hline - Yes & 1240 & 477 & 38.5 & $3.03(2.70-3.40)$ & $<0.001$ \\
\hline
\end{tabular}

*The reference category of the dependent variable was good SROA. ** Mean (standard deviation) of the quantitative variables. Permanent teeth present: total sample, 5.75 (8.05); poor, 6.95 (7.78); and good, 5.43 (8.10). Decayed permanent teeth: total sample, 1.28 (2.98); poor, 2.60 (4.36); and good, 0.93 (2.39).

lower prosthesis and among those who never used dental services, visited a dentist more than 3 years ago, did not have access to information about oral problem prevention, had more decayed teeth, selfrated the need for dental treatment, reported dental and gingival pain within the last 6 years, showed poor chewing ability, or affirmed that their oral health affected their relationships with other people.
The prevalence of poor SROA was lowest among those aged 70-74 years. Two main associations were observed with the 2 variables reflecting the perception of health, i.e., poor chewing ability and self-perception of the need for dental treatment (Table 3).

\section{Discussion}

The prevalence of poor SROA, represented by 
Table 3 - Final Poisson regression model.

\begin{tabular}{|c|c|c|}
\hline & Adjusted PR (95\% Cl) & $p$ value \\
\hline \multicolumn{3}{|c|}{ Age range } \\
\hline $65-69$ & 1 & \\
\hline $70-74$ & $0.87(0.78-0.98)$ & 0.021 \\
\hline \multicolumn{3}{|c|}{ Type of dental service } \\
\hline Private & 1 & \\
\hline Public & $1.14(1.02-1.29)$ & 0.025 \\
\hline Never used & $1.58(1.26-1.98)$ & $<0.001$ \\
\hline \multicolumn{3}{|c|}{ Access to information about oral problem prevention } \\
\hline Yes & 1 & \\
\hline No & $1.14(1.01-1.28)$ & 0.034 \\
\hline \multicolumn{3}{|c|}{ Time since the last dental visit } \\
\hline$\leq 2$ years & 1 & \\
\hline$\geq 3$ years & $1.20(1.06-1.36)$ & 0.003 \\
\hline \multicolumn{3}{|c|}{ Need for upper prosthesis } \\
\hline Does not need & 1 & \\
\hline Needs a fixed or RPP & $1.33(1.13-1.56)$ & 0.001 \\
\hline Needs a complete prosthesis & $1.18(1.01-1.39)$ & 0.042 \\
\hline \multicolumn{3}{|c|}{ Need for lower prosthesis } \\
\hline Does not need & 1 & \\
\hline Needs a fixed or RPP & $1.21(1.01-1.45)$ & 0.042 \\
\hline Needs a complete prosthesis & $1.25(1.04-1.50)$ & 0.019 \\
\hline Number of decayed teeth & $1.10(1.01-1.20)$ & 0.022 \\
\hline \multicolumn{3}{|c|}{ Self-perception of the need for dental treatment } \\
\hline No & 1 & \\
\hline Yes & $1.70(1.46-1.98)$ & $<0.001$ \\
\hline \multicolumn{3}{|c|}{ Dental and gingival pain within the last 6 months } \\
\hline Absent & 1 & \\
\hline Present & $1.22(1.08-1.37)$ & $<0.001$ \\
\hline \multicolumn{3}{|c|}{ Chewing ability } \\
\hline Good & 1 & \\
\hline Poor & $3.02(2.57-3.54)$ & $<0.001$ \\
\hline \multicolumn{3}{|c|}{ Oral health affects relationships with other people } \\
\hline No & 1 & \\
\hline Yes & $1.37(1.21-1.55)$ & $<0.001$ \\
\hline
\end{tabular}

a mean of 26.03 missing teeth, was low despite the overall poor oral health conditions of subjects. Elderly Germans also self-reported high satisfaction with their oral appearance ${ }^{13}$ but had a lower median number of lost (14.2) and decayed (0.5) teeth than the Brazilian elderly. ${ }^{14}$ In the United Kingdom, $80.3 \%$ of the population aged $\geq 55$ years were satisfied with their teeth color; ${ }^{15}$ however, aesthetics were addressed with preconceived standards of what is beautiful and acceptable. The low prevalence of poor SROA may be explained by the fact that $81.4 \%$ of the edentate elderly used an upper prosthesis and $62.8 \%$ used a lower prosthesis. ${ }^{8}$ In a previous study, the importance of dental prostheses for enhancing appearance was observed because the elderly used these devices to create a satisfactory appearance even when they did not fit well. ${ }^{16}$

The present study confirmed the theoretical model of Meng et al. ${ }^{9}$, as variables in all of the groups showed a significant association with SROA. The need for dental prostheses was associated with SROA, independent of other variables. Dental prostheses can restore oral appearance to an acceptable state $^{17}$ and minimize the adverse effects of tooth loss by improving self-esteem and interpersonal relationships ${ }^{18}$ because the elderly associate good appearance with the ability to communicate and make social connections. ${ }^{19}$ Furthermore, aesthetics are the main reasons for the use of prostheses among participants. ${ }^{20}$ Thus, concerns about replacing lost teeth are greater when aesthetics are involved, ${ }^{11}$ necessitating the consideration of the psychological and social aspects of dental loss during prosthetic rehabilitation for the elderly.

The number of decayed teeth and the self-perception of the need for dental treatment were also associated with SROA. Dissatisfaction with the appearance of teeth was previously associated with self-related anterior decayed, ${ }^{21}$ stained, or broken teeth, ${ }^{9}$ which may compromise self-perception of appearance and damage self-esteem. The significant and strong association between poor SROA and self-perception of the need for dental treatment was expected, as elderly people who perceive a need for dental treatment are likely to have other negative psychosocial effects of oral health conditions.

Age was the only sociodemographic variable associated with poor SROA, and SROA was lower among the subjects in the oldest age group. This finding may be attributed to the argument that younger people actively try to improve their physi- 
cal appearance to obtain a better job and gain greater social acceptance..$^{15}$ Older people, on the other hand, may more easily incorporate poorer dental appearance in their self-image and may have a low desire to make changes. ${ }^{15}$

The 3 variables related to dental services were associated with SROA. Elderly adults who had never used dental services or used them infrequently were more likely to have a poor SROA. These variables were associated with poor self-rated oral health among elderly Brazilians. ${ }^{4-6}$ Irregular or infrequent users of dental services had more carious teeth than regular users ${ }^{22}$ and lost more teeth than regular users. $^{23}$ Thus, routine visits can help preserve functional dentition, thereby improving the perception of appearance. Moreover, dental visits might reassure and inform people, boosting their confidence regarding their oral health condition, rendering them more likely to report the positive aspects of their oral health. ${ }^{24}$ Elderly people who used public dental services showed a higher prevalence of poor SROA. In Brazil, historically, this group did not receive public dental care service, except in cases of urgency, resulting in dental mutilation. Moreover, for many years, prosthetic treatment under public health services was not offered to the elderly population, thus worsening their oral health status.

The higher prevalence of poor SROA among those who felt that oral health affected interpersonal relationships highlights its importance in

\section{References}

1. Gilbert L. Social factors and self-assessed oral health in South Africa. Community Dent Oral Epidemiol. 1994 Feb;22(1):4751.

2. Locker D. Applications of self-reported assessments of oral health outcomes. J Dent Educ. 1996 Jun;60(6):494-500.

3. Martins AMEB, Barreto SM, Pordeus IA. [Objective and subjective factors related to self-rated oral health among the elderly]. Cad Saude Publica. 2009 Feb;25(2):421-35. Portuguese

4. Patussi MP, Peres KG, Boing AF, Peres MA, Costa JSD. Selfrated oral health and associated factors in Brazilian elders. Community Dent Oral Epidemiol. 2010 Aug;38(4):348-59.

5. Martins AMEB, Barreto SM, Silveira MF, Santa-Rosa TT, Pereira RD. Self-perceived oral health among Brazilian elderly individuals. Rev Saude Publica. 2010 Oct;44(5):912-22. social interactions. Poor SROA was also greater among those who had experienced pain in the last 6 months or among those who were unsatisfied with their chewing ability. These individuals likely experienced a common oral health condition involving a lack of teeth or the presence of teeth in a precarious state, which had a negative impact on various aspects of oral health.

The advantages of our analysis are the large sample size and high response rate. The main methodological consideration involved sample selection using the cluster sampling technique. Although sample weights were not calculated, this procedure would not affect the magnitudes or direction of the identified associations..$^{25}$ The results of this study support the present oral health policy in Brazil, which aims to provide dental prostheses to all the elderly as part of the Brazilian public dentistry health service. Improvements in the quality of preventative information, access to dental services, treatment of decayed teeth, and rehabilitation with dental prosthesis may contribute to greater satisfaction with appearance, especially among those elderly who experience dental and gingival pain, those who perceive a need for dental treatment, and those with impaired chewing ability.

\section{Conclusion}

The elderly who needed dental prostheses showed higher prevalence of poor self-rated oral appearance than those who did not need any.

6. Locker D, Clarke M, Payne B. Self-perceived oral health status, psychological well-being, and life satisfaction in an older adult population. J Dent Res. 2000 Apr;79(4):970-5.

7. Brasil. Ministério da Saúde. Condições de saúde bucal da população brasileira 2002-2003: resultados principais [Internet]. Brasília (DF): Ministério da Saúde; 2005 [cited 2012 Oct 29]. 68p. Available from: http://dtr2001.saude.gov.br/editora/ produtos/livros/pdf/05_0053_M.pdf. (Série C. Projetos, Programas e Relatórios).

8. Dias-da-Costa JS, Galli R, Oliveira EA, Backes V, Vial EA, Canuto R, et al. [Prevalence of poor self-rated mastication and associated factors in Brazilian elderly]. Cad. Saude Publica. 2010 Jan;26(1):79-88. Portuguese. 
9. Meng X, Gilbert GH, Duncan RP, Heft MW. Satisfaction with dental appearance among diverse groups of dentate adults. $\mathrm{J}$ Aging Health. 2007 Oct;19(5):778-91.

10. Osterberg T, Hedergard B, Sater G. Variation in dental health in 70 -year oldmen and women in Goteborg, Sweden. A crosssectional epidemiological study including longitudinal and cohort effects. Swed Dent J. 1984;8(1):29-48.

11. Kokich VO Jr, Kiyak HA, Shapiro PA. Comparing the perception of dentists and lay people to altered dental esthetics. J Esthet Dent. 1999 Nov;11(6):311-24.

12. World Health Organization. Oral health surveys: basic methods. Geneva: WHO; 1997.

13. Hassel AJ, Wegener I, Rolko C, Nitschke I. Self-rating of satisfaction with dental appearance in an elderly German population. Int Dent J. 2008 Apr;58(2):98-102.

14. Crocombe LA, Mejia GC, Koster CR, Slade GD. Comparison of adult oral health in Australia, The USA, Germany and the UK. Aust Dent J. 2009 Jun;54(2):147-53.

15. Alkhatibe MN, Holt R, Bedi R. Age and perception of dental appearance and tooth color. Gerodontology. 2005 Mar;22(1):32-6.

16. Rodrigues SM, Vargas AMD, Moreira NA. [Self-perception of oral health among elderly]. Arq. Odontol. 2003;39(3):163254. Portuguese.

17. Ferreira AAA, Piuvezam G, Werner CWA, Alves MSCF. [The toothache and toothloss: social representation of oral care]. Cien Saude Colet. 2006 Jan/Mar;11(1):211-18. Portuguese.

18. Sheiham A, Steele JC, Marcenes W, Tsakos G, Finch S, Walls AW. Prevalence of impacts of dental and oral disorders and their effects on eating among older people; a national survey in Great Britain. Community Dent Oral Epidemiol. 2001 Jun;29(3):195-203.

19. Reis SCG, Marcelo VC. [Oral health in old age: elderly's perceptions, Goiânia, 2005]. Cien Saude Colet. 2006 JanMar;11(1):191-9. Portuguese.

20. Elias AC, Sheiham A. The relationship between satisfaction with mouth and number, position and condition of teeth: studies in Brazilian adults. J Oral Rehabil. 1999 Jan;26(1):53-71.

21. Samorodnitzky-Naveh GR, Geiger SB, Levin LL. Patients' satisfaction with dental esthetics. J Am Dent Assoc. 2007 Jun;138(6):805-8.

22. Davenport C, Elley K, Salas C, Taylor-Weetman CL, FrySmith A, Bryan $\mathrm{S}$ et al. The clinical effectiveness and costeffectiveness of routine dental checks: a systematic review and economic evaluation. Health Technol Assess. 2003;7(7):1-27

23. Cunha-Cruz J, Nadanovsky P, Faerstein E, Lopes CS. Routine dental visits are associated with tooth retention in Brazilian adults: the Pro-Saude study. J Public Health Dent. 2004 Fall;64(4):216-22.

24. Afonso-Souza G, Nadanovsky P, Chor D, Faerstein E, Werneck GL, Lopes CL. Association between routine visits for dental checkup and self-perceived oral health in an adult population in Rio de Janeiro: the Pró-Saúde study. Community Dent Oral Epidemiol. 2007 Oct;35(5):393-400.

25. Narvai PC, Antunes JLF, Moysés SJ, Frazão P, Peres MA, Peres KG, et al. [Scientific validity of epidemiological knowledge based on data from the Brazilian Oral Health Survey (SB Brazil 2003)]. Cad Saude Publica. 2010 Apr;26(4):647-70. Portuguese. 